\title{
High dose alfentanil pre-empts pain after abdominal hysterectomy
}

\author{
Joel Katza,c,d,*, Michel Clairoux ${ }^{b, 1}$, Cormac Redahan ${ }^{b}$, Brian P. Kavanagh ${ }^{b, d}$, Sandra Carroll , \\ Hilary Nierenberg ${ }^{b}$, Marla Jackson ${ }^{\mathrm{a}}$, Jane Beattie ${ }^{\mathrm{b}}$, Anna Taddio ${ }^{\mathrm{e}}$ and Alan N. Sandler $\mathrm{r}^{\mathrm{b}, \mathrm{d}}$ \\ ${ }^{a}$ Department of Psychology and ${ }^{b}$ Department of Anaesthesia, The Toronto Hospital, Toronto. Ontario, MSG 2 C4 (Cunada), ${ }^{c}$ Department of Behavioural \\ Science, ${ }^{\mathrm{d} D e p a r t m e n t ~ o f ~ A n a e s t h e s i a, ~ a n d ~}{ }^{\mathrm{E} D e p a r t m e n t}$ of Pharmacy, University of Toronto, Toronto, Ontario MSS IA8 (Canada)
}

\begin{abstract}
Summary This study tested the hypothesis that high dose systemic alfentanil administered before and during abdominal hysterectomy would pre-empt post-operative pain to a greater extent than administration of either low dose alfentanil or no alfentanil perioperatively. Patients (ASA 1 or 2) were randomly assigned to group $1(n=15)$, no opioid; group 2 ( $n=15$ ), low dose alfentanil; or group 3 $(n=15)$, high dose alfentanil. Anaesthesia was induced in group 1 with midazolam and thiopentone and was maintained with isoflurane and $70 \% \mathrm{~N}_{2} \mathrm{O}$ in $\mathrm{O}_{2}$. Anaesthesia was induced in group 2 with midazolam, thiopentone and i.v. alfentanil (30 $\left.\mu \mathrm{g} \mathrm{kg} \mathrm{g}^{-1}\right)$, and was maintained with isoflurane, $70 \% \mathrm{~N}_{2} \mathrm{O}$ in $\mathrm{O}_{2}$, and bolus doses of $\mathrm{i} . \mathrm{v}$. alfentanil (10-20 $\mu \mathrm{g} \mathrm{kg}^{-1}$ ) every hour. Anaesthesia was induced in group 3 with midazolam and i.v. alfentanil $\left(100 \mu \mathrm{g} \mathrm{kg}^{-1}\right)$, and was maintained with $70 \% \mathrm{~N}_{2} \mathrm{O}$ in $\mathrm{O}_{2}$, and an infusion of i.v. alfentanil (1-2 $\mu \mathrm{g} \mathrm{kg}$ $\min ^{-1}$ ). Blood samples were drawn at 30 and 120 min after surgery and assayed for plasma alfentanil. Morphine consumption and VAS pain scores were consistently lowest in group 3 over the $48 \mathrm{~h}$ study period. A composite measure of pain and morphine consumption was significantly lower in group 3 than group 2 up to $6 \mathrm{~h}$ after surgery, and significantly lower than group 1 up to $12 \mathrm{~h}$. No adverse effects were observed. A 6-month follow-up did not reveal any significant differences among the three groups. It is concluded that intra-operative high dose alfentanil anaesthetic pre-empts post-operative pain after abdominal hysterectomy, but the effects are small and of short duration. Surgical procedures carried out under general anaesthesia using standard (and even high) doses of opioids intraoperatively provide suboptimal protection from the injury barrage brought about by incision and subsequent noxious surgical events.
\end{abstract}

Key words: Pre-emptive analgesia; Post-operative pain; Alfentanil; Hysterectomy; Inflammation

\section{Introduction}

Although the pre-operative administration of opioids has a long history in anaesthesiology, only recently has this well established practice been evaluated for potential analgesic effects that extend beyond the duration of action of the opioids. The rationale for predicting an extended analgesic effect is derived from animal studies showing that morphine prevents the establishment of injury-induced central sensitization when given before but not after injury (Woolf and Wall 1986). The clinical implication of these results is that the central sensitization that is presumed to develop as a consequence of surgical trauma leads to an amplification of peripheral input and increased post-

\footnotetext{
* Corresponding author: Joel Katz, Department of Psychology, The Toronto Hospital, General Division, 200 Elizabeth St., CW 2-306, Toronto, Ontario, M5G 2C4 Canada. Tel.: (1) 416-3403777; Fax: (1) 416-3404739; E-mail: j.katz@utoronto.ca

1 Present address: Département d'anesthésie et réanimation, C.H.U.S., 300112 ième avenue nord, Fleurimont, Québec, J1H 5N4, Canada.
}

operative pain intensity (Wall 1988; Coderre et al. 1993; Woolf and Chong 1993)

We recently demonstrated that pre-incisional treatment with epidural fentanyl in patients undergoing thoracotomy resulted in significantly lower pain and morphine consumption compared with patients that received the same treatment after incision.(Katz et al. 1992a). These results indicate that it is possible to pre-empt post-operative pain with epidural opioids. The question of whether systemic opioids pre-empt post-operative pain when given before versus after incision or surgery also has been addressed (Richmond et al. 1993; Mansfield et al. 1994; Wilson et al. 1994; Collis et al. 1995; Fassoulaki et al. 1995). The results of these studies are equivocal, with two showing reduced pain and/or analgesic consumption following pre- but not post-surgical administration of opioids (Richmond et al. 1993; Collis et al. 1995) and others showing no effect (Mansfield et al. 1994; Wilson et al. 1994; Fassoulaki et al. 1995). Methodological flaws and insufficient data presentation make it difficult to interpret these results. However, taken together, it appears that with doses routinely adminis- 
tered during surgery under general anaesthesia, systemic opioids may not produce a sufficiently dense blockade of noxious peri-operative inputs to prevent central sensitization in either the pre- or post-incisional group.

While the ability of systemic opioids to pre-empt postoperative pain may be limited when administered as a supplement to general anaesthesia, it is nonetheless possible that they create subtle pre-emptive effects which reduce post-operative pain to a level that could make it difficult to distinguish the pre-emptive benefits of a target treatment (e.g. local anaesthetic infiltrations, nerve blocks, epidural or spinally administered local anaesthetics or opioids) given before versus after surgery (Katz 1995). For example, a number of recent studies evaluating the pre-emptive analgesic effects of regional anaesthesia combined with general anaesthesia have not found the expected reduction in post-operative pain or analgesic requirements among patients that received regional anaesthesia before versus after surgery (Dahl et al. 1992; Dierking et al. 1992; Pryle et al. 1993). However, in these studies all patients also received systemic opioids as pre-medication, at induction of the general anaesthetic, or during surgery. The possibility cannot be ruled out that the pre-operative administration of systemic opioids to all patients attenuated the development of CNS sensitization in all patients and contributed to the lack of a clinically significant outcome between pre- and post-treated groups (Katz et al. 1992b, 1993). In contrast, studies that have shown a benefit of pre-incisional local anaesthetic infiltration.(Ejlersen et al. 1992) or epidural analgesia/anaesthesia (Katz et al. 1992a, 1994) over postincisional administration of the same agents by the same route have not administered systemic opioids before or during surgery. Taken together, these results suggest that routine use of systemic opioids at induction of general anaesthesia and during surgery may provide subtle preemptive analgesic effects that might make it difficult to demonstrate a significant difference in post-operative pain and analgesic requirements between pre- and posttreated patients. The present study was therefore undertaken in part to evaluate the pre-emptive effects of low dose systemic alfentanil relative to a no-opioid control group.

The present study was also designed to evaluate whether the pre-emptive analgesic effect of systemic opioids is dose-dependent. Collis et al. (1995) reported that $20 \mathrm{mg}$ of morphine administered before surgery did not appear to offer an obvious advantage compared with their previous study (Richmond et al. 1993) in which $10 \mathrm{mg}$ of morphine was administered, but the two doses were not compared in a single study. Thus, we do not know whether increasing the pre-emptive dose of an opioid will correspondingly increase the clinical benefit when compared with a smaller dose. In order to evaluate these aims, we compared the preemptive analgesic effects of low and high dose alfentanil in women undergoing abdominal hysterectomy with a control group that did not receive alfentanil.

\section{Material and methods}

Approval to carry out the study was obtained from the Toronto Hospital Committee for Research on Human Subjects. All patients gave their written informed consent to participate before entering the study.

\section{Patient selection}

Patients (ASA physical status 1-2) scheduled for total abdominal hysterectomy with or without bilateral salpingo-oopherectomy were included in the study. Exclusion criteria were ASA physical status $>2$, age less than 18 or greater than 80 years, weight $\geq 75 \mathrm{~kg}$, non-English speaking, and history of major psychopathology.

\section{Randomization and blinding procedures}

Before the start of the study, a computer-generated randomization schedule was used to specify the group ( $1=$ no opioid, $2=$ low dose alfentanil, or $3=$ high dose alfentanil) to which each prospective patient would be assigned upon entry into the trial (Dallal 1988). An envelope containing the group assignment was prepared, sealed and numbered for each prospective patient. On the morning of the surgery, the anaesthesiologist in charge of the case opened the patient's envelope, read its contents, and prepared the syringes of alfentanil for subsequent administration.

All patients and personnel involved in patient management and data collection were unaware of the group to which the patient had been assigned. The only individual who was not blinded was the anaesthesiologist in charge of the case who was not involved in the patient's postoperative care or data collection.

\section{Pre-operative assessment}

The day before surgery, patients were interviewed by a member of the Acute Pain Research Unit. Patients were familiarized with the visual analogue pain scale (VAS) and were introduced to the patient-controlled analgesia (PCA) pump and carefully instructed in its use.

\section{General anaesthesia}

All patients received diazepam p.o. (5-10 mg) $2 \mathrm{~h}$ prior to surgery as pre-medication. Patients were assigned at random to one of three groups. As detailed below, group I did not receive opioids, group 2 received low dose alfentanil and group 3 received high dose alfentanil. After induction of anaesthesia, all patients had a radial arterial catheter inserted for postoperative blood sampling to measure plasma alfentanil levels and arterial blood gases.

For patients in group 1, anaesthesia was induced with i.v. midazolam $\left(0.05 \mathrm{mg} \mathrm{kg}^{-1}\right)$ and thiopentone $\left(3-5 \mathrm{mg} \mathrm{kg}^{-1}\right)$. Muscle relaxation and tracheal intubation were facilitated with vecuronium $\left(0.1-0.15 \mathrm{mg} \mathrm{kg}^{-1}\right)$. Anaesthesia was maintained with isoflurane and $70 \% \mathrm{~N}_{2} \mathrm{O}$ in $\mathrm{O}_{2}$. Opioids were not administered at induction or intra-operatively.

For patients in group 2, anaesthesia was induced with i.v. alfentanil $\left(30 \mu \mathrm{g} \mathrm{kg}^{-1}\right.$ ), i.v. midazolam $\left(0.05 \mathrm{mg} \mathrm{kg}^{-1}\right.$ ), and thiopentone (3-5 mg $\mathrm{kg}^{-1}$ ). Muscle relaxation and tracheal intubation were facilitated with vecuronium $\left(0.1-0.15 \mathrm{mg} \mathrm{kg}^{-1}\right)$. Anaesthesia was maintained with $70 \%$ $\mathrm{N}_{2} \mathrm{O}$ in $\mathrm{O}_{2}$, isoflurane and bolus doses of $i . v$. alfentanil $\left(10-20 \mu \mathrm{g} \mathrm{kg}^{-1}\right)$ every hour. For groups 1 and 2 , isoflurane was titrated to maintain systolic blood pressure within $20 \%$ of baseline systolic blood pressure derived from pre-operative ward measurements.

For patients in group 3, anaesthesia was induced with i.v. midazolam $(0.05 \mathrm{mg} \mathrm{kg}-1)$ and i.v. alfentanil $\left(100 \mu \mathrm{g} \mathrm{kg}^{-1}\right)$. Muscle relaxation and tracheal intubation were facilitated with vecuronium $\left(0.1-0.15 \mathrm{mg} \mathrm{kg}^{-1}\right)$. Anaesthesia was maintained with $70 \% \mathrm{~N}_{2} \mathrm{O}$ in $\mathrm{O}_{2}$ and a continuous infusion of i.v. alfentanil $\left(1-2 \mu \mathrm{g} \mathrm{kg}^{-1} \cdot \mathrm{min}^{-1}\right)$. The alfentanil dose was adjusted to maintain hemodynamic variables within $20 \%$ of pre-operative ward values by administering a bolus dose of i.v. alfentanil $(10-20 \mu \mathrm{g}$ $\mathrm{kg}^{-1}$ ) and increasing the alfentanil infusion by increments of $0.25-0.5 \mu \mathrm{g}$ $\mathrm{kg}^{-1} \min ^{-1}$. The alfentanil infusion was discontinued $30 \mathrm{~min}$ before the anticipated end of surgery. 
Patients received propranolol $(0.5-1.0 \mathrm{mg})$ if tachycardia or hypertension was not controlled by the above regimens. At the conclusion of the surgery, neuromuscular blockade was reversed with neostigmine $\left(0.05 \mathrm{mg} \mathrm{kg}^{-1}\right)$ and glycopyrrolate $\left(0.01 \mathrm{mg} \mathrm{kg}^{-1}\right)$. The trachea was extubated after emergence and upon resumption of spontaneous breathing. Patients received supplemental $\mathrm{O}_{2}$ by mask and were transported to the postanaesthetic care unit (PACU).

\section{Peri-operative monitoring}

All patients were continuously monitored throughout the procedure with a non-invasive blood pressure cuff, electrocardiogram, pulse oximeter, temperature probe, nerve stimulator and end-tidal carbon dioxide and anaesthetic agent analyzer. For groups $\mathfrak{I}$ and 2 , mean end-tidal isoflurane concentration was calculated for each 5 min block beginning after induction of anaesthesia until the end of surgery.

\section{Post-operative management}

Patients were assessed immediately upon arrival in the PACU. A PCA pump system (Abbott Life Care Infuser, Chicago, IL) was connected to the indwelling i.v. cannula. Every $10 \mathrm{~min}$, patients were asked whether they were in need of pain relief. An affirmative response was followed by a $2 \mathrm{mg}$ intravenous bolus of morphine administered by a nurse observer who was unaware of the group to which the patients had been assigned. This procedure was repeated until the patients were alert enough to begin using the PCA pump. The PCA pump was set to deliver a 1.5-2.0 mg intravenous bolus dose of morphine with a lock-out time of 5-7 min, a maximum dose of $30 \mathrm{mg}$ in any $4 \mathrm{~h}$ period, and no continuous background infusion. This regimen was overseen by the Acute Pain Service (APS) and was continued on the ward for $48 \mathrm{~h}$ during which no other analgesics were administered. APS personnel were unaware of the group to which patients had been assigned. Morphine (mg) usage was calculated from hard copy records (Abbott TRW Printer Model TP 40).

\section{Post-operative pain measurement}

A 10-cm VAS (with endpoints labelled 'no pain' and 'worst possible pain') was used to assess pain intensity at rest (VAS-R) 2, 4, 6, 12, 24 and $48 \mathrm{~h}$ after the completion of surgery. Pain after movement (VAS-M) was assessed at 24 and $48 \mathrm{~h}$ by asking patients to sit up from a lying position and perform two maximal inspirations using an incentive spirometer before rating their pain.

Pain was also assessed at 24 and $\mathbf{4 8} \mathrm{h}$ using the McGill Pain Questionnaire (MPQ).(Melzack 1975). The MPQ consists of 20 sets of words, each containing from two to six adjectives that describe the sensory, affective, or evaluative properties of pain. The list of pain descriptors was read to the patient who chose the words that best described her pain at the moment. The MPQ yields two global scores, the pain rating index (PRI) and the present pain intensity (PPI). The total pain rating index (PRI-T) is the sum of the rank values of the descriptors chosen from the 20 sets. The PPI is rated on a scale of $0-5$ as follows: $0=$ no pain, $1=$ mild, $2=$ discomforting, $3=$ distressing, $4=$ horrible, $5=$ excruciating.

\section{Plasma alfentanil concentrations and pharmacokinetics}

Blood samples $(10 \mathrm{cc})$ were drawn in all patients from a radial artery at $30 \mathrm{~min}$ and $120 \mathrm{~min}$ after arrival in the PACU. Samples were collected in heparinized glass vials, centrifuged immediately, and the separated plasma stored at $-27^{\circ} \mathrm{C}$ until analysis at the end of the study. Assays were performed by a blinded technician on samples obtained from patients in groups 2 and 3 only. Concentrations of alfentanil were measured in duplicate using a specific radioimmunoassay kit (Janssen Biotech NV Research Products). The sensitivity of the assay is $0.1 \mathrm{ng} \mathrm{ml}^{-1}$ and the intraand inter-assay coefficients of variation covering the therapeutic range of concentrations are $<10 \%$,(Michiels et al. 1983).

Pharmacokinetic parameters were calculated using standard procedures (Gibaldi and Perrier 1982). Plasma alfentanil half-life was calculated for each patient using the formula $t_{1 / 2}=0.693 / k$, where $k$ is the elimination rate constant. The elimination rate constant was determined by the formula $k=\ln C_{1}-\ln C_{2} /\left(t_{2}-t_{1}\right)$, where $C_{1}$ and $C_{2}$ are plasma alfentanil concentrations taken 30 and $120 \mathrm{~min}$ after surgery, respectively. Plasma alfentanil concentrations $\left(C_{\mathrm{j}}\right)$ were extrapolated to 4,6 , and $12 \mathrm{~h}$ after surgery using the following formula for describing firstorder elimination: $C_{\mathrm{j}}=C_{2} \mathrm{e}^{-\mathrm{k}\left(\mathrm{t}_{\mathrm{j}}-\mathrm{t}_{2}\right)}$.

\section{Post-operative follow-up}

Six months after surgery, patients were contacted by telephone by a research assistant who was unaware of the group to which the patient had been assigned at the time of surgery. A brief, standardized questionnaire was administered to each patient assessing the presence and intensity of pain at the site of the scar at rest and after movement. All patients rated the pain on a 0-10-point verbal rating scale (VRS) with endpoints specified as 'no pain' and 'worst possible pain'. All patients also rated their pain using the PPI scale of the MPQ.(Melzack 1975).

The interviewer assessed whether certain movements were associated with pain onset or exacerbation. Specifically, patients were asked to run their finger along the scar, to take a deep breath and cough, and to sit up from a lying position. Patients rated the ensuing pain after each of these manoeuvres using a 0 -10-point VRS.

\section{Statistical analysis}

Demographic, clinical, and intra-operative treatment variables were analyzed by chi-squared test (frequency data) or one-way, betweengroups ANOVA (parametric data)

VAS-R, VAS-M, MPQ scores, and an integrated analgesic assessment score, consisting of a composite measure of VAS-R and PCA morphine consumption (Silverman et al. 1993) were analyzed by non-parametric Kruskal Wallis ANOVA of ranks. Significant effects were followed up with non-parametric Student-Newman-Keuls multiple comparison procedure (Glantz 1992) to determine the pattern of significance among the three groups. The integrated analgesic assessment score.(Silverman et al. 1993) is calculated by separately rank ordering pain scores and morphine consumption, obtaining a difference score for each individual rank by subtracting it from its mean, expressing the difference score as a percentage of the mean rank, and summing the \% differences for pain and morphine. This procedure yields a composite pain and morphine score that represents the \% difference from the mean overall rank (i.e. $0 \%$ ) and ranges between $-200 \%$ (most comfortable) and $+200 \%$ (least comfortable).

One-way, between-groups ANOVA with Bonferroni's correction ( $\alpha$ / number of tests) was used to analyze morphine consumed within intervals bounded by the times when pain assessments were carried out. Significant effects were followed up with Tukey's post-hoc tests to determine the pattern of differences between pairs of means. Cumulative morphine consumption at $48 \mathrm{~h}$ was analyzed by one-way ANOVA. Plasma alfentanil concentrations were analyzed by two-way repeated measures ANOVA using group $(2,3)$ as the independent samples factor and time (30 $\mathrm{min}$ and $120 \mathrm{~min}$ ) as the repeated measures factor. Terminal alfentanil half-life was analyzed by two-tailed, unpaired $t$-test.

Long-term follow up data were analyzed by chi-squared test for freguency data and Kruskal-Wallis ANOVA of ranks. All data are presented as mean \pm SD unless otherwise specified. $P<0.05$ is considered statistically significant.

\section{Results}

\section{Patient withdrawals}

Fifty-one patients were recruited in order to achieve a sample size of 15 patients per group. In total, six patients were withdrawn from the study. One patient received additional analgesics from personnel not involved in the study $5 \mathrm{~h}$ after surgery, three developed complications necessitat- 
TABLE I

MEAN (SD) CLINICAL, DEMOGRAPHIC, AND INTRAOPERATIVE TREATMENT VARIABLES FOR THE THREE GROUPS

\begin{tabular}{lccc}
\hline & Group 1 & Group 2 & Group 3 \\
\hline ASA status $^{\mathrm{a}}(1: 2)$ & $15: 0$ & $13: 2$ & $12: 3$ \\
Age (years) & $41.4(7.8)$ & $46.1(5.9)$ & $45.9(7.6)$ \\
Weight (kg) & $62.7(7.8)$ & $66.3(11.6)$ & $67.9(9.2)$ \\
Surgery duration (min) & $86.5(35.2)$ & $84.0(30.4)$ & $90.1(26.5)$ \\
Blood loss (ml) & $213(158.6)$ & $369(421.6)$ & $439(484.8)$ \\
Total alfentanil (mg) & 0.0 & $3.31(0.55)$ & $17.48(5.92)$ \\
Propranolol (mg) & $0.53(0.14)$ & 0.0 & 0.0 \\
Isoflurane $^{\mathrm{b}}(\%)$ & $1.2(0.27)$ & $0.88(0.16)$ & 0.0 \\
\hline
\end{tabular}

"Number of patients classified as status 1 and 2 .

${ }^{b}$ Mean end-tidal isoflurane concentration in 5 min blocks.

ing further surgery, and two were withdrawn due to intraoperative protocol violations.

\section{Demographic, clinical and intra-operative treatment variables}

The three groups did not differ significantly on demographic variables (Table I) or in frequency of diagnosis, incision type or surgical procedure (Table II). Group 3 received significantly more alfentanil than group 2 $(F(1,28)=85.1, \quad P<0.0001)$. Mean isoflurane requirements were significantly greater in group 1 than group 2 $(F(1,28)=14.0, P<0.001)$. Nine patients in group 1 received propranolol $\left(\chi^{2}(2)=22.5, P=0.0001\right)$.

\section{Pain and morphine consumption}

VAS-R pain scores were consistently lowest in the high dose group across the entire $48 \mathrm{~h}$ study period (Fig. 1). VAS-R was significantly lower for group 3 than group 1 at $2 \mathrm{~h}(P=0.003)$ and $4 \mathrm{~h}(P=0.01)$ and significantly lower for group 2 than group 1 at $4 \mathrm{~h}(P=0.02)$ after surgery. VAS-M pain scores did not differ significantly among the three groups (Table III). Morphine consumption was significantly lower in group 3 than either of the two other

TABLE II

FREQUENCY OF DIAGNOSIS, PROCEDURE AND TYPE OF INCISION FOR THE THREE GROUPS

\begin{tabular}{lccc}
\hline & Group 1 & Group 2 & Group 3 \\
\hline $\begin{array}{l}\text { Diagnosis } \\
\text { Fibroids }\end{array}$ & 8 & 13 & 11 \\
Endometrial carcinoma & 2 & 1 & 1 \\
Endometriosis & 2 & 0 & 3 \\
PMS & 3 & 1 & 0 \\
Procedobdominal pain & & & \\
Total abdominal hysterectomy & 12 & 11 & 12 \\
Total abdominal hysterectomy & 3 & 4 & 3 \\
$\quad+$ bilateral salpingo-oophorectomy & & & \\
Type of incision & & & \\
Horizontal & 10 & 9 & 8 \\
Midline & 5 & 6 & 7 \\
\hline
\end{tabular}

aPMS = pre-menstrual syndrome.

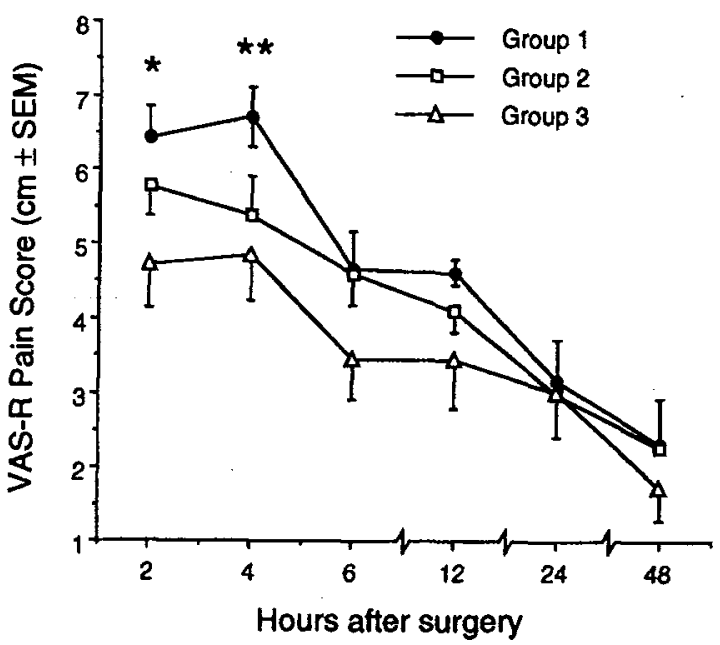

Fig. 1. Mean visual analogue pain scores at rest (VAS-R) for the three groups. ${ }^{*} P=0.003$ for group 1 versus $3,{ }^{* *} P=0.02$ for group 1 versus 2 and $P=0.01$ for group 1 versus 3 .

groups (both $P<0.05$ ) between $0 \mathrm{~h}$ and $2 \mathrm{~h}$ after surgery (Fig. 2). At the conclusion of the study, $48 \mathrm{~h}$ after surgery, cumulative morphine $(\mathrm{mg})$ was $108.1 \pm 52.5,96.7 \pm 41.4$, and $91.1 \pm 35.3$ for groups 1,2 and 3, respectively (Table IV).

Use of the composite measure of VAS-R and PCA morphine consumption maximized the differences in analgesic effect among the three groups (Fig. 3). The integrated analgesic assessment scores for group 3 were significantly lower than the two other groups at $2 \mathrm{~h}, 4 \mathrm{~h}$, and $6 \mathrm{~h}$ after surgery (all $P<0.05)$ and lower than group 1 at $12 \cdot \mathrm{h}(P=$ 0.05 ).

McGill Pain Questionnaire PRI-T scores did not differ significantly among the three groups (Table V). Table VI shows the MPQ descriptors chosen by more than $33 \%$ of patients in the three groups $24 \mathrm{~h}$ and $48 \mathrm{~h}$ after surgery. Overall, significantly fewer patients in group 3 endorsed descriptors indicative of pain when compared with the other two groups $\left(\chi^{2}(1)=4.4, P=0.04\right)$.

\section{Plasma levels of alfentanil}

Plasma levels of alfentanil were available at $30 \mathrm{~min}$ and $120 \mathrm{~min}$ after surgery for 10 patients in group 2 and 11 patients in group 3 (Table VII). The ANOVA showed a significant main effect of group $(F(1,19)=25.3, P<$ $0.0001)$, time $(F(1,19)=97.6, P<0.0001)$ and a significant group by time interaction $(F(1,19)=37.8, P<$ $0.0001)$. Examination of the interaction showed that the

\section{TABLE III}

MEAN (SD) VAS PAIN SCORES FOR THE THREE GROUPS AFTER STANDARD MOBILIZATION (VAS-M)

\begin{tabular}{llll}
\hline Time after surgery $(\mathrm{h})$ & Group 1 & Group 2 & Group 3 \\
\hline 24 & $5.5(2.0)$ & $5.1(2.5)$ & $5.0(2.8)$ \\
48 & $5.2(2.1)$ & $4.1(2.1)$ & $4.4(2.5)$ \\
\hline
\end{tabular}




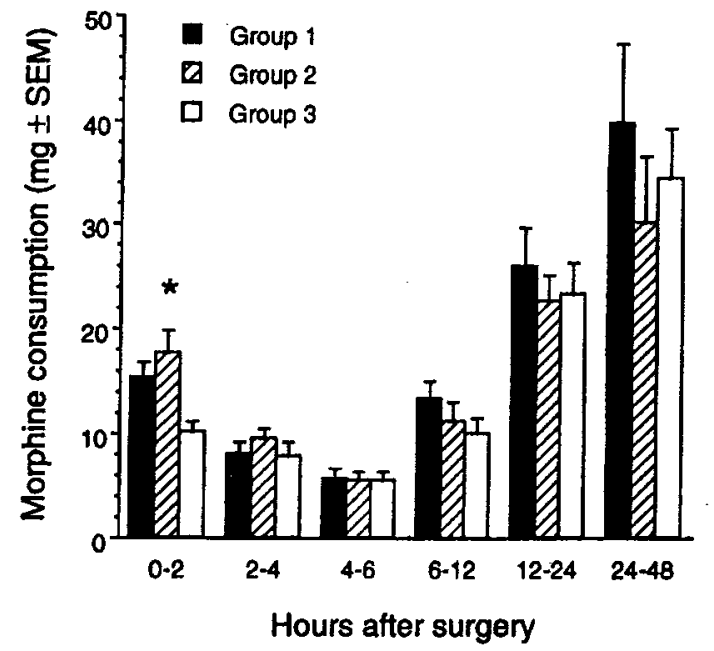

Fig. 2. Mean PCA morphine consumption for the three groups within time intervals bounded by VAS-R pain assessments. ${ }^{*} P<0.05$ for group 1 versus 2 and group 1 versus 3 .

alfentanil plasma level in group 3 was significantly greater than that of group 2 at $30 \mathrm{~min}(F(1,20)=32.2, P<0.0001)$ and $120 \mathrm{~min}(F(1,19)=20.1, P<0.0001)$. In addition, plasma levels decreased significantly from $30 \mathrm{~min}$ to $120 \mathrm{~min}$ in group $2(F(1,9)=45.7, P<0.0001)$ and group $3(F(1,10)=76.2, P<0.0001)$.

The mean terminal half-life of alfentanil was estimated to be $2.8 \pm 1.3 \mathrm{~h}$ and $1.8 \pm 0.9 \mathrm{~h}$ for the high and low dose alfentanil groups, respectively $(t(19)=2.1, P=0.05)$. We extrapolated plasma levels out to $12 \mathrm{~h}$ after surgery based on the terminal half-life. Table VII shows estimated mean plasma concentrations in the high dose group $4 \mathrm{~h}, 6 \mathrm{~h}$, and $12 \mathrm{~h}$ after surgery.

\section{Adverse effects}

No adverse effects were observed.

\section{Six month follow-up}

Of the 45 patients who completed the study, 38 were contacted by telephone and interviewed 6 months after surgery. Three patients in group 1, two in group 2, and two in group 3 could not be reached. One patient in group 2 who was contacted was subsequently excluded because she had undergone three additional abdominal surgeries in the

TABLE IV

MEAN (SD) CUMULATIVE PCA MORPHINE (MG) CONSUMPTION FOR THE THREE GROUPS

\begin{tabular}{lcll}
\hline Time after surgery $(\mathrm{h})$ & Group 1 & Group 2 & Group 3 \\
\hline 2 & $15.3(6.1)$ & $17.7(7.9)$ & $10.1(3.9)$ \\
4 & $23.2(8.7)$ & $27.3(10.7)$ & $18.0(7.0)$ \\
6 & $28.8(11.2)$ & $32.7(13.1)$ & $23.4(9.6)$ \\
12 & $42.2(16.1)$ & $43.9(16.6)$ & $33.5(11.8)$ \\
24 & $68.2(28.0)$ & $66.5(24.2)$ & $56.7(20.1)$ \\
48 & $108.1(52.5)$ & $96.7(41.4)$ & $91.1(35.3)$ \\
\hline
\end{tabular}

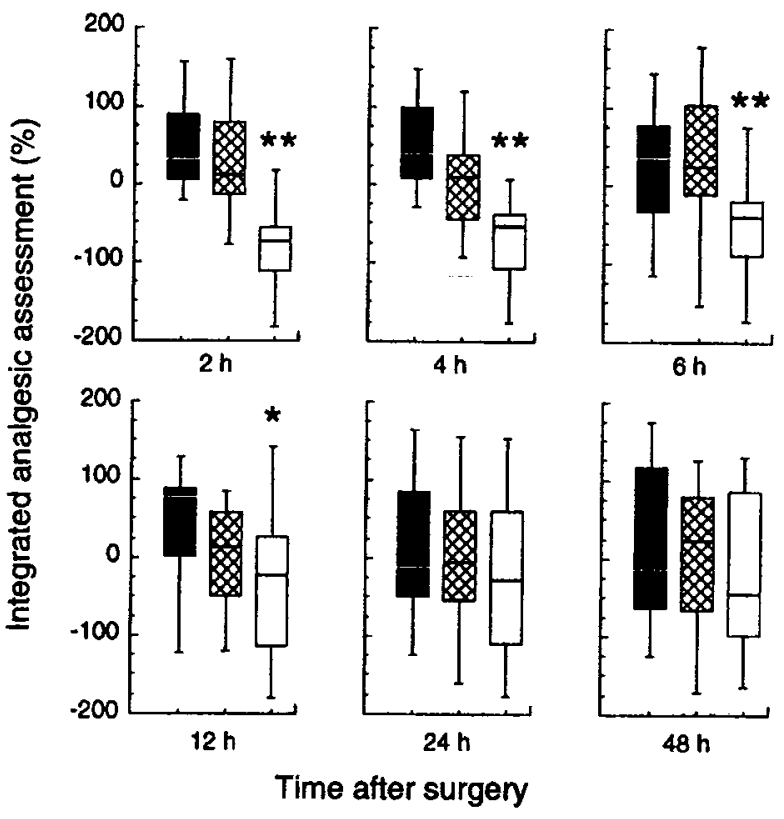

Fig. 3. Box-and-whisker plots of the integrated analgesic assessment scoring method consisting of a composite measure of VAS pain scores at rest and PCA morphine consumption. The median is identified by the centre horizontal line partitioning the box. The first and third quartiles are at the ends of the box (i.e. $50 \%$ of the observations fall within the box). The extreme values identify $1.5 \times$ interquartile range. Groups 1,2 , and 3 are symbolized by black, cross-hatched, and white boxes, respectively. ${ }^{*} * P<0.05$ for group $\mid$ versus 3 and group 2 versus $3 ; * P<0.05$ for group 1 versus 3.

intervening 6 months. Table VIII shows the frequency and intensity of pain experienced by the three groups. Spontaneous pain at rest was reported by three patients (one in group 1 and two in group 3) all of whom localized the pain to the scar. The number of patients reporting evoked pain (having patients run a finger along the scar, sit up, and cough) did not differ among the three groups.

\section{Discussion}

The results of the present study support the hypothesis

TABLE V

MEAN (SD) MPQ SCORES FOR THE THREE GROUPS 24 AND $48 \mathrm{H}$ AFTER SURGERY SHOWING THE TOTAL PRI, PPI, AND TOTAL NUMBER OF WORDS CHOSEN (TOTAL WORDS).

\begin{tabular}{lccc}
\hline & Group I & Group 2 & Group 3 \\
\hline $24 h$ & & & \\
Total PRI & $22.4(14.1)$ & $22.7(14.5)$ & $14.5(12.6)$ \\
PPI & $1.9(0.9)$ & $1.7(0.8)$ & $1.6(1.1)$ \\
Total words & $13.2(10.2)$ & $12.1(6.4)$ & $8.7(8.9)$ \\
$48 h$ & & & \\
Total PRI & $12.5(10.7)$ & $14.3(10.2)$ & $15.5(14.1)$ \\
PPI & $1.4(1.0)$ & $1.5(0.8)$ & $1.4(0.9)$ \\
Total words & $7.6(6.4)$ & $9.1(6.8)$ & $8.6(8.3)$ \\
\hline
\end{tabular}


TABLE VI

MPQ DESCRIPTORS CHOSEN BY ONE-THIRD OR MORE OF PATIENTS IN THE THREE GROUPS 24 AND $48 \mathrm{H}$ AFTER SURGERY

\begin{tabular}{lllccc}
\hline $\begin{array}{l}\text { Time } \\
\text { (h) }\end{array}$ & $\begin{array}{l}\text { MPQ } \\
\text { class }\end{array}$ & $\begin{array}{l}\text { MPQ } \\
\text { descriptor }\end{array}$ & $\begin{array}{l}\text { Group 1 } \\
(\%)\end{array}$ & $\begin{array}{l}\text { Group 2 } \\
(\%)\end{array}$ & $\begin{array}{l}\text { Group 3 } \\
(\%)\end{array}$ \\
\hline 24 & Sensory & Throbbing & 46 & - & - \\
& & Shooting & 38 & 33 & - \\
& & Stabbing & 38 & - & - \\
& & Cutting & - & 33 & - \\
& & Cramping & - & 47 & - \\
& & Pulling & - & 60 & - \\
& & Aching & - & 33 & - \\
& Affective & Tender & 62 & 60 & 36 \\
& & Tiring & - & - & 36 \\
& & Exhausting & 62 & 60 & - \\
& & Sickening & 38 & 33 & - \\
48 & Miscell. & Nauseating & - & 53 & - \\
& Sensory & Cramping & 36 & - & - \\
& & Itchy & 50 & - & - \\
& & Tender & 43 & 43 & 38 \\
& Affective & Tiring & - & 36 & 46 \\
& Miscell. & Tight & - & 36 & - \\
\hline
\end{tabular}

Miscell. $=$ miscellaneous.

that administration of i.v. alfentanil before and during surgery pre-empts post-operative pain after abdominal hysterectomy but the effects are small and of relatively short duration. Pain and morphine consumption were consistently lowest for group 3 across the $48 \mathrm{~h}$ assessment period. The composite measure of pain and morphine consumption was significantly lower in group 3 than group 1 up to $12 \mathrm{~h}$ after surgery at a time when the estimated mean plasma concentration of alfentanil in the high dose group was below the minimum effective analgesic plasma concentration for awake patients in the early post-operative period.(Camu et al. 1982; Persson et al. 1988). In addition, results from the MPQ, 24 and $48 \mathrm{~h}$ after surgery, showed that fewer patients in group 3 than in the two other groups endorsed descriptors indicative of pain. However, 6 months after surgery the three groups could not be distinguished on the basis of pain incidence.

The analgesic effects of alfentanil in awake subjects are dose-related (Hill et al. 1986). The mean minimum effec-

\section{TABLE VII}

MEAN (SD) OBSERVED (30 AND 120 MIN) AND EXTRAPOLATED (4, 6 AND $12 \mathrm{H}$ ) PLASMA ALFENTANIL CONCENTRATIONS (NG $\mathrm{ML}^{-1}$ ) FOR GROUPS 2 AND 3

\begin{tabular}{lcc}
\hline Time after surgery & Group 2 & Group 3 \\
\hline $30 \mathrm{~min}$ & $35.2(14.4)$ & $231.7(113.1)$ \\
$120 \mathrm{~min}$ & $18.5(10.9)$ & $160.2(99.1)$ \\
$4 \mathrm{~h}^{\mathrm{a}}$ & $9.0(7.3)$ & $101.9(80.7)$ \\
$6 \mathrm{~h}^{\mathrm{a}}$ & $4.7(4.6)$ & $67.0(63.4)$ \\
$12 \mathrm{~h}^{\mathrm{a}}$ & $0.85(1.1)$ & $21.8(28.3)$ \\
\hline
\end{tabular}

${ }^{2}$ Plasma concentrations at $4 \mathrm{~h}, 6 \mathrm{~h}$, and $12 \mathrm{~h}$ are estimates based on the terminal half- life calculated from the $30 \mathrm{~min}$ and $120 \mathrm{~min}$ values. See text for details.
TABLE VIII

SIX-MONTH FOLLOW-UP DATA SHOWING FREQUENCY AND INTENSITY OF PAIN FOR THE THREE GROUPS

\begin{tabular}{llll}
\hline & $\begin{array}{l}\text { Group I } \\
(n=12)\end{array}$ & $\begin{array}{l}\text { Group 2 } \\
(n=12)\end{array}$ & $\begin{array}{l}\text { Group 3 } \\
(n=13)\end{array}$ \\
\hline Months since surgery & $6.3(0.3)$ & $6.6(0.9)$ & $6.3(0.5)$ \\
Pain at time of interview $(n)$ & 1 & 0 & 2 \\
VRS at time of interview & 7.5 & 0 & $1.0(1.4)$ \\
Pain in past week $(n)$ & 6 & 2 & 7 \\
VRS for past week & $3.4(2.4)$ & $6.0(1.4)$ & $2.4(1.5)$ \\
PPI for past week & $1.3(0.5)$ & $3.0(1.4)$ & $1.1(0.4)$ \\
Pain when touches scar $(n)$ & 1 & 1 & 1 \\
Pain when sits up $(n)$ & 1 & 0 & 4 \\
Pain when coughs $(n)$ & 0 & 1 & 3 \\
\hline
\end{tabular}

All data represent mean (SD) values unless otherwise specified.

tive analgesic plasma concentration in the early postoperative period has been reported to range from approximately $35 \mathrm{ng} \mathrm{ml}^{-1}$ to $56 \mathrm{ng} \mathrm{ml}^{-1}$.(Persson et al. 1988; Camu and Debucquoy 1991). In order to evaluate whether the observed differences in analgesia might have been due to the presence of therapeutic alfentanil concentrations, we extrapolated alfentanil concentrations to $12 \mathrm{~h}$ after surgery. The estimated concentration of $21.8 \mathrm{ng} \mathrm{ml}^{-1}$ for the high dose group $12 \mathrm{~h}$ after surgery was lower than the reported minimum effective analgesic plasma concentration. In addition, given the significant difference in half-life between groups 2 and 3 , it is likely that alfentanil undergoes saturation pharmacokinetics with high doses. The difference in half-life was not explained by patient characteristics such as age, weight, surgery duration, or procedure, supporting the suggestion that the higher dose led to nonlinear pharmacokinetics. These considerations suggest that the estimation of plasma alfentanil concentrations by a monoexponential function (i.e. first-order elimination) probably resulted in an overestimate of the actual alfentanil concentration at $12 \mathrm{~h}$. Blood sampling at a later time (i.e. when enzyme systems were not saturated) may have resulted in a shorter half-life due to changes in clearance rate relative to alfentanil concentrations. Thus, the significantly lower composite measure of pain and morphine consumption in group 3 compared with group 212 hours after surgery is likely due to a true pre-emptive analgesic effect rather than a lingering pharmacological effect of alfentanil.

The evidence for a clear-cut, dose-dependent preemptive analgesic effect is less convincing. A pre-emptive effect of low dose alfentanil was demonstrated at $4 \mathrm{~h}$ since VAS-R pain scores were lower in group 2 compared with group 1 at a time when cumulative morphine consumption did not differ significantly between the two groups and when the estimated mean plasma alfentanil concentration in group $2\left(9.0 \mathrm{ng} \mathrm{ml}^{-1}\right)$ was sub-therapeutic. As discussed above, the pre-emptive effect of high dose alfentanil was observed $12 \mathrm{~h}$ after surgery when the integrated analgesic assessment scores in group 3 were significantly lower than group 1. More importantly, at $2 \mathrm{~h}, 4 \mathrm{~h}$, and $6 \mathrm{~h}$ after sur- 
gery, the integrated analgesic assessment scores in group 3 were significantly lower than in group 2 , suggesting a dose-dependent effect. However, we cannot be certain that these latter differences reflect a pre-emptive analgesic effect since actual $(2 \mathrm{~h})$ and estimated $(4 \mathrm{~h}$ and $6 \mathrm{~h}$ ) plasma levels of alfentanil in group 3 appeared to be above the effective analgesic concentration reported (Camu et al. 1982; Persson et al. 1988).

The results of the present study confirm and extend the findings by Kiss and Killian (1992), Richmond et al. (1993), and Collis et al. (1995). The mechanism(s) by which systemic alfentanil pre-empted pain are not known but there are at least two possibilities. One is that noxious peri-operative inputs induced a state of central neural sensitization in group 1 which amplified inputs from the wound and led to enhanced post-operative pain intensity and increased requirements for morphine. Systemic administration of alfentanil in groups 2 and 3 before and during surgery attenuated the noxious central neural effects of surgery relative to group 1 so that pain and morphine requirements were reduced in the early post-operative period.

Another explanation for the observed pre-emptive analgesic effect is based on evidence that systemic administration of $\mu$ opioid agonists reduces injury-induced inflammation and plasma extravasation by their peripheral and central actions.(Joris et al. 1990; Barber and Gottschlich 1992; Gavalas et al. 1994; Stein 1995). According to this possibility, administration of alfentanil may have exerted a preemptive effect by reducing the extent of peripheral inflammation and, hence, pain in groups 2 and 3 relative to group 1. Thus, it may be that systemic opioids pre-empt post-operative pain by more than one mechanism. In addition to attenuating the effects of the afferent barrage associated with surgery, it is possible that opioids act by reducing the extent of peripheral inflammation following surgery.

When this possibility is considered in conjunction with the finding that inflammation increases the anti-nociceptive potency of $\mu$-opioid agonists such as morphine and fentanyl (Stanfa et al. 1992; Antonijevic et al. 1995; Ossipov et al. 1995), it raises questions about how to interpret the lack of a difference in cumulative PCA morphine consumption among the three groups. If development of inflammation is attenuated by systemic opioids and if the potency of morphine increases in the presence of inflammation, then compared to group 3, group 1 would have developed a greater degree of inflammation and pain, but would not have required more morphine to reduce the pain to an intensity comparable to group 3 (due to increased morphine potency in the presence of inflammation). It is not inconceivable, therefore, that the magnitude of the preemptive analgesic effect in group 3 was underestimated, since groups 1 and 3 would be expected to have selfadministered similar amounts of morphine even though inflammation-induced pain might have been more intense in group 1. In general, using a fixed post-operative analgesic regimen and looking for inter-group differences in pain intensity .(see e.g. Tverskoy et al. 1990, 1994) would obviate this potential problem and provide a more direct test of the predictions of pre-emptive analgesia; namely, reduced pain when resting and moving about.

The pre-emptive analgesic effect observed in the present study appears to conflict with the results of three studies which failed to find differences in post-operative pain intensity or morphine consumption in favour of patients treated with low dose systemic opioids before versus after incision (Mansfield et al. 1994; Wilson et al. 1994; Fassoulaki et al. 1995). However, differences in the design, opioid doses, and conduct of the studies may explain the inconsistent outcomes.

In the study by Wilson et al. (1994) patients received either alfentanil $40 \mu \mathrm{g} \mathrm{kg}^{-1} 10 \mathrm{~min}$ before and saline $1 \mathrm{~min}$ after skin incision, or saline $10 \mathrm{~min}$ before and alfentanil $40 \mu \mathrm{g} \mathrm{kg}^{-1} 1 \mathrm{~min}$ after skin incision. The absence of differences between the groups in post-operative morphine consumption and pain at $24 \mathrm{~h}$ may be confirmation, in the clinical setting, of the findings by. Wall and Woolf (1984) that high intensity noxious stimulation of $\mathrm{C}$-fibre afferents located in skin is considerably less effective in inducing prolonged central facilitation than stimulation of afferents located in deep tissue. Since alfentanil was administered only $1 \mathrm{~min}$ after skin incision in the post-incisional group, it is unlikely that damage had been done to deeper tissues which contain the $\mathrm{C}$-fibre afferents responsible for inducing long-lasting central neural hyperexcitability.

The administration of alfentanil after only $1 \mathrm{~min}$ of nociceptive input raises the question of the time course of central sensitization and whether hyperexcitability can be prevented by an early post-incisional treatment. Electrophysiological studies in rats have shown that second-phase formalin responses of dorsal horn nociceptive neurons are inhibited to the same degree when a $\mu$-opioid agonist is administered intrathecally before or shortly (i.e. $9 \mathrm{~min}$ ) after formalin injury.(Chapman et al. 1994). However, preinjury administration is significantly more effective at inhibiting second-phase responses than late (i.e. $30 \mathrm{~min}$ ) post-injury administration. One implication of these findings for clinical studies is that administration of $\mu$-opioid agonists may be equally effective before and after incision until central sensitization has developed but once established, higher doses may be required post-surgery to provide the same degree of post-operative pain relief. In the study by Wilson et al. (1994), it is likely that central sensitization had not fully developed by $1 \mathrm{~min}$ after incision, suggesting that the pre-emptive analgesic potential of alfentanil was missed by virtue of too early an intervention postincision.

In addition, in the study by Wilson et al. (1994), all patients received morphine $0.1 \mathrm{mg} \mathrm{kg}^{-1} 1 \mathrm{~min}$ after incision. This means that patients in the two groups were not treated identically with respect to the timing of opioid administra- 
tion relative to incision. This criticism applies to the study by Mansfield et al. (1994) as well. Finally, although cumulative PCA morphine consumption did not differ between the groups, pain ratings were not obtained until $24 \mathrm{~h}$ after surgery. The presence of inter-group differences in pain intensity within the first $24 \mathrm{~h}$ would have been missed. Post-operative PCA morphine consumption is not a substitute measure of pain. Factors other than pain govern the amount of morphine patients self-administer. These include extent of adverse effects (nausea, pruritis, drowsiness) as well as psychological variables. In light of our past.(Katz et al. 1992a; Kavanagh et al. 1994a) and present results, as well as those of others (Silverman et al. 1993), it is clear that both pain and analgesic consumption must be measured in order to obtain an accurate appraisal of patient comfort.

Mansfield et al. (1994) administered $15 \mu \mathrm{g} \mathrm{kg}^{-1}$ alfentanil before or $10 \mathrm{~min}$ after incision. In addition, both groups received $0.2 \mathrm{mg} \mathrm{kg} \mathrm{kg}^{-1}$ morphine $10 \mathrm{~min}$ after incision. Differences in post-operative pain intensity or morphine consumption between the groups were not detected at $2 \mathrm{~h}, 6 \mathrm{~h}$ or $24 \mathrm{~h}$ after surgery. Given the relatively small pre-emptive effect observed in group 2 patients in the present study using twice the dose of alfentanil $\left(30 \mu \mathrm{g} \mathrm{kg}^{-1}\right)$, the lack of a pre-emptive effect in the study by Mansfield et al. (1994) is, as the authors themselves point out, likely due to an insufficient dose of alfentanil in combination with the administration of morphine to all patients after incision.

In the study by Fassoulaki et al.,(1995), fentanyl (10 $\mu \mathrm{g}$ $\left.\mathrm{kg}^{-1}\right)$ or sufentanil $\left(1 \mu \mathrm{g} \mathrm{kg}^{-1}\right)$ was administered before or after incision or surgery. Post-operatively, pain was measured every $30 \mathrm{~min}$ until the first request for analgesia. Patients were then placed on a fixed analgesic regimen for the duration of the study. The pre-incisional groups did not show the anticipated pre-emptive analgesic effect. However, as with the study by Wilson et al..(1994), the presence of inter-group differences in pain intensity would have been missed since pain was not assessed between the time patients first requested analgesics and the end of the study. There were no significant inter-group differences in time from skin closure to first analgesic request, but this measure is not meaningful in studies of pre-emptive analgesia which evaluate the timing of opioid administration relative to incision. A more appropriate measure would be time from administration of the opioid to the first request.

The most obvious difference between the present study and those carried out by Wilson et al. (1994), Mansfield et al. . (1994) and Fassoulaki et al. (1995) is our omission of post-incisional alfentanil treatments. This may be an important factor in explaining the inconsistent results since we do not know the time course of central sensitization in the post-operative setting or whether it can be prevented or significantly attenuated by an early (e.g. $1 \mathrm{~min}$ or $10 \mathrm{~min}$ ) post-injury treatment. Elsewhere, we have argued that use of the term pre-emptive analgesia to refer exclusively to evidence that pre-operative treatment is more effective than post-operative treatment (as opposed to no treatment or a placebo treatment) is too restrictive and narrow (Katz 1995). It has been argued that evidence of pre-emptive analgesia requires control of the same intervention made after surgery .(McQuay 1992), but in doing so, it may not be possible, or even desirable, to ensure that the groups are treated similarly with respect to other anaesthetic agents (e.g. see Katz et al. 1994).

Demonstrating that pre-treatment with analgesic agents, but not a placebo, lessens pain and decreases post-operative analgesic requirements at a time when the agents are no longer clinically active, suggests that the central component of post-operative pain can be prevented or pre-empted. In the absence of a post-incisional or post-operative control condition, it may not be possible to determine whether factors associated with the intra-operative or post-operative period (or both) are necessary for the enhanced postoperative pain experience. Nevertheless, in the absence of a post-treatment condition, the finding that pain or analgesic consumption is reduced relative to an untreated control condition is evidence of a pre-emptive analgesic effect providing the agent administered pre-emptively is no longer clinically active.

In spite of the many differences in design and methodology, the results of pre-emptive studies using systemic opioids suggest that routine pre- and intra-operative doses of systemic opioids do not provide sufficient blockade of the nociceptive barrage during surgery to prevent the development of central sensitization. This is consistent with recent animal experiments (Abram and Olson 1994). However, low dose opioids given before or during surgery do create subtle pre-emptive effects which reduce postoperative pain to a level that would make it difficult to distinguish a beneficial effect of a target treatment given before versus after surgery (Katz 1995; Yashpal et al. 1996). Our previous work in this area suggests that the epidural route.(Katz et al. 1992a, 1994) may be more effective than other routes (Kavanagh et al. 1994b), perhaps because it provides more direct access to and blockade of spinal neurons responsible for the processing and transmission of nociceptive information.

The small pre-emptive analgesic effects observed in the present study, coupled with the high dose of alfentanil required to demonstrate these effects, suggest that the findings are more of mechanistic than practical significance. However, the lack of a clinically significant pre-emptive effect is itself notable, since this implies that surgical procedures carried out under general anaesthesia using standard (and even high) doses of opioids intraoperatively provide sub-optimal protection from the injury barrage brought about by incision and subsequent noxious surgical events. This conclusion is supported by the high pain scores observed immediately after surgery in the group that received high dose alfentanil perioperatively. 
In conclusion, administration of high dose alfentanil during abdominal hysterectomy led to reduced pain and morphine consumption up to $6 \mathrm{~h}$ after surgery when compared with a low dose alfentanil group and up to $12 \mathrm{~h}$ when compared with a group that did not receive systemic opioids during surgery. A subtle pre-emptive analgesic effect was detected at $4 \mathrm{~h}$ after surgery in the low dose group relative to untreated controls, suggesting that routine doses of systemic opioids administered before and during surgery do contribute to reduced post-operative pain hours later. Overall, high dose patients appeared to be more comfortable $24 \mathrm{~h}$ after surgery as evidenced by fewer patients endorsing descriptors indicative of pain on the MPQ. The incidence and intensity of pain 6 months after surgery did not differ significantly among the three groups. The safety of the high dose alfentanil regimen is confirmed by the absence of adverse effects, and is predictable in this healthy patient population, given the pharmacokinetic profile of alfentanil. The requirement for propranolol in group 1 supports the role of moderate and high-dose alfentanil regimens in achieving and maintaining intra-operative hemodynamic stability.

\section{Acknowledgements}

The authors are grateful for the help provided by the staff of the Department of Anaesthesia, Department of Gynaecological Surgery, and Post Anaesthetic Care Unit. Supported by a Medical Research Council of Canada (MRC) Scholarship and MRC Grant MT-12052 to Joel Katz.

\section{References}

Abram, S.E. and Olsen, E.E., Systemic opiods do not suppress spinal sensitization after subcutaneous formalin in rats, Anesthesiology, 80 (1994) $1114-1119$

.Antonijevic, 1., Mousa, S.A., Schafer, M. and Stein, C., Perineural defect and peripheral opioid analgesia in inflammation, J. Neurosci., 15 (1995) 165-172.

Barber, A. and Gottschlich, R., Opioid agonists and antagonists: an evaluation of their peripheral actions in inflammation, Med. Res. Rev., 12 (1992) 525-562.

Camu, F. and Debucquoy, F., Alfentanil infusion for postoperative pain: a comparison of epidural and intravenous routes, Anesthesiology, 75 (1991) 171-178.

Camu, F., Gepts, E., Rucquoi, M. and Heykants, J., Pharmacokinetics of alfentanil in man, Anesth. Analg., 61 (1982) 657-661.

Chapman, V., Haley, J.E. and Dickenson, A.H., Electrophysiological analysis of preemptive effects of spinal opioids on $\mathrm{N}$-methyl-D-aspartate receptor-mediated events, Anesthesiology, 81 (1994) 1429-1435.

Coderre, T.J., Katz, J., Vaccarino, A.L. and Melzack, R., Contribution of central neuroplasticity to pathological pain: review of clinical and experimental evidence, Pain, 52 (1993) 259-285.

Collis, R., Brandner, B., Bromley, L.M. and Woolf, C.J., Is there any clinical advantage of increasing the pre-emptive dose of morphine or combining pre-incisional with post-incisional morphine administration? Br. J. Anaesth., 74 (1995) 396-399.
Dahl, J.B., Hansen, B.L., Hjortsø, N.C., Erichsen, C.J., Møiniche, S. and

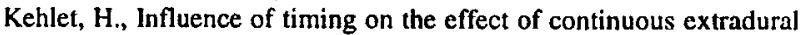
analgesia with bupivacaine and morphine after major abdominal surgery, Br. J. Anaesth., 69 (1992) 4-8.

Dallal, G.E., DESIGN: A supplementary module for SYSTAT and SYGRAPH, SYSTAT, Evanston, IL, 1988.

Dierking, G.W., Dahl, J.B., Kanstrup, J., Dahl, A. and Kehlet, H., Effect of pre- vs. postoperative inguinal field block on postoperative pain after herniorraphy, Br. J. Anaesth., 68 (1992) 344-348.

Ejlersen, E., Bryde Anderson, H., Eliasen, K. and Mogensen, T., A comparison between preincisional and postincisional lidocaine infiltration and postoperative pain, Anesth. Analg., 74 (1992) 495-498.

Fassoulaki, A., Sarantopolous, C., Zotou, M. and Papoulia, D., Preemptive opioid analgesia does not influence pain after abdominal hysterectomy, Can. J. Anaesth., 42 (1995) 109-113.

Gavalas, A., Victoratos, P., Yiangou, M., Hadjipetrou-Kourounakis, L., Rekka, E. and Kourounakis, P., The anti-inflammatory effect of opioids, Int. J. Neurosci., 74 (1994) 259-264.

Gibaldi, M. and Perrier, D., Pharmacokinetics, Dekker, New York, 1982.

Glantz, S.A., Primer of Biostatistics (3rd edn.), McGraw-Hill, New York, 1992.

Hill, H., Walter, H., Saeger, L., Sargur, M., Sizemore, W. and Chapman, C.R., Dose effects of alfentanil in human analgesia, Clin. Pharmacol. Ther., 40 (1986) 178-186.

Joris, J., Costello, A., Dubner, R. and Hargreaves, K.M., Opiates suppress carrageenan-induced edema and hyperthermia at doses that inhibit hyperalgesia, Pain, 43 (1990) 95-103.

Katz, J., Pre-emptive analgesia: evidence, current status and future directions, Eur. J. Anaesthesiol., 12 (Suppl. 10) (1995) 8-13.

Katz, J., Kavanagh, B.P. and Sandler, A.N., Effect of pre-operative opioid administration on post-operative pain, Br. J. Anaesth., 69 (1992a) 424.

Katz, J., Kavanagh, B.P., Sandler, A.N., Nierenberg, H., Boylan, J.F., Friedlander, M. and Shaw, B.F., Preemptive analgesia: clinical evidence of neuroplasticity contributing to post-operative pain, Anesthesiology, 77 (1992b) 439-446.

Katz, J., Kavanagh, B.P., Clairoux, M. and Sandler, A.N., Pre-emptive analgesia, Br. J. Anaesth., 70 (1993) 378.

Katz, J., Clairoux, M., Kavanagh, B.P., Roger, S., Nierenberg, H., Redahan, C. and Sandler, A.N., Pre-emptive lumbar epidural anaesthesia reduces postoperative pain and patient-controlled morphine consumption after lower abdominal surgery, Pain, 59 (1994) 395-403.

Kavanagh, B.P., Katz, J., Sandler, A.N., Nierenberg, H., Roger, S., Boylan, J.F. and Laws, A.K., Multimodal analgesia before thoracic surgery does not reduce postoperative pain, Br. J. Anaesth., 73 (1994a) 184-189.

Kavanagh, B.P., Katz, J. and Sandler, A.N., Pain control after thoracic surgery: a review of current techniques, Anesthesiology, 81 (1994b) 737-759.

Kiss, I.E. and Kilian, M., Does opiate premedication influence postoperative analgesia? A prospective study, Pain, 48 (1992) 157-158.

Mansfield, M., Meikle, R. and Miller, C., A trial of pre-emptive analgesia: influence of timing of peroperative alfentanil on postoperative pain and analgesic requirements, Anaesthesia, 49 (1994) 1091-1093.

McQuay, H.J., Pre-emptive analgesia, Br. J. Anaesth., 69 (1992) 1-3.

Melzack, R., The McGill Pain Questionnaire: major properties and scoring methods, Pain, 1 (1975) 277-299.

Michiels, M., Hendriks, R. and Heykants, J., Radioimmunoassay of the new opiate analgesics alfentanil and sufentanil: preliminary pharmacokinetics profile in man, J. Pharm. Pharmacol., 35 (1983) 86-93.

Ossipov, M.H., Kovelowski, C.J. and Porreca, F., The increase in morphine antinociceptive potency produced by carrageenan-induced hindpaw inflammation is blocked by naltrindole, a selective deltaopioid antagonist, Neurosci. Lett., 184 (1995) 173-176.

Persson, M.P., Nilsson, A. and Hartvig, P., Pharmacokinetics of alfentanil in total I.V. anaesthesia, Br. J. Anaesth., 60 (1988) 755-761.

Pryle, B.J., Vanner, R.G., Enriquez, N. and Reynolds, F., Can pre- 
emptive epidural blockade reduce postoperative pain following lower abdominal surgery? Anaesthesia, 48 (1993) 120-123.

Richmond, C.E., Bromley, L.M. and Woolf, C.J., Preoperative morphine pre-empts postoperative pain, Lancet, 342 (1993) 73-75.

Silverman, D.G., O'Connor, T.Z. and Brull, S.J., Integrated assessment of pain scores and rescue morphine use during studies of analgesic efficacy, Anesth. Analg., 77 (1993) 168-170.

Stanfa, L.C., Sullivan, A.F. and Dickenson, A.H., Alterations in neuronal excitability and the potency of spinal mu, delta and kappa opioids after carrageenan-induced inflammation, Pain, 50 (1992) 345354.

Stein, C., The control of pain in peripheral tissue by opioids, N. Engl. J. Med., 332 (1995) 1685-1690.

Tverskoy, M.. Cozacov, C., Ayache, M., Bradley, E.L. and Kissin, I., Postoperative pain after inguinal hemiorraphy with different types of anesthesia, Anesth. Analg., 70 (1990) 29-35.

Tverskoy, M., Oz, Y., Isakson, A., Finger, J., Bradley, E.L. and Kissin, L., Preemptive effect of fentanyl and ketamine on postoperative pain and wound hyperalgesia, Anesth. Analg., 78 (1994) 205-209.
Wall, P.D., The prevention of post-operative pain, Pain, 33 (1988) 289 290.

Wall, P.D. and Woolf, C.J., Muscle but not cutaneous C-afferent input produces prolonged increases in the excitability of the flexion reflex in the rat, J. Physiol. (London), 356 (1984) 443-458.

Wilson, R.J.T., Leith, S., Jackson, I.J.B. and Hunter, D., Pre-emptive analgesia from intravenous administration of opioids: no effect with alfentanil, Anaesthesia, 49 (1994) 591-593.

Woolf, C.J. and Chong, M.S., Preemptive analgesia: treating postoperative pain by preventing the establishment of central sensitization, Anesth. Analg., 77 (1993) 362-379.

Woolf, C.J. and Wall, P.D., Morphine-sensitive and morphine-insensitive actions of C-fibre input on the rat spinal cord, Neurosci. Lett., 64 (1986) 221-225.

Yashpal, K., Katz, J. and Coderre, T.J., The effects of pre-emptive or post-injury intrathecal local anesthesia on persistent nociceptive responses in rats: confounding influences of peripheral inflammation and the general anesthetic regimen, Anesthesiology, 84 (1996) 11191128. 